\title{
Spectrum of Malignant Lymphoma in a Tertiary Care Hospital of North Eastern India
}

\author{
Mondita Borgohain*, Gayatri Gogoi, Niva Sharma, Upam Sharma, Kamal Kishore Chelleng and Jyoti Bikash Saikia \\ Department of Pathology, Assam Medical College \& Hospital, Dibrugarh(India)
}

\begin{abstract}
Background: The term malignant Lymphomas embrace a variable group of Proliferative diseases that originate in the Lymph node or extra nodal Lymphatic Tissue. It constitutes 3.69\% of all Malignancies World Wide. The incidence of Lymphoma exhibits a marked Geographic variation in the World.

Methods: The study included58 patients who were histologically diagnosed as Malignant lymphomas in our hospital, the paraffin embedded blocks of these cases were evaluated by a panel of immunohistochemistry markers by taking proper controls and using the standard protocol. Statistical analysis were performed by SPSS software.

Results: Out of the 58 cases of Malignant Lymphoma 47 were diagnosed as Non Hodgkins Lymphoma and 11 cases (19\%) as Hodgkins Lymphoma. Of these 58 cases of Malignant Lymphoma, adults were 51 and paediatric cases were 7, male female ratio was 2.6:1 and Non Hodgkins Lymphoma was Commoner. B cell Lymphomas were the predominant type accounts for 74.5\% of all Non Hodgkins Lymphoma cases of these B cell Lymphomas Diffuse large B cell Lymphoma was the Predominant type.

Among the T cell Lymphomas Anaplastic large cell Lymphoma was the commonest subtype. Nodular Sclerosis Cases were seen most commonly in the Hodgkins Category. Extra nodal Lymphomas were also seen in $35.6 \%$ cases with Tonsil being the commonest site.
\end{abstract}

Conclusion: Non Hodgkins Lymphoma was significantly more common in this region and diffuse large B cell Lymphoma was the predominant type. A combination of Histopathology and a Meticulous Immunohistochemistry helps in properly solving the diagnostic challenges.

\section{Keywords: Malignant Lymphoma, Non Hodgkins Lymphoma, Hodgkins Lymphomas, Diffuse large B cell Lymphoma, Histopathology, Immunohistochemistry.}

\section{Introduction}

Malignant Lymphoma are a diverse group of Malignancies arising from Band $\mathrm{T}$ Lymphocytes and are generally categorized as either Hodgkins Lymphoma or Non Hodgkins Lymphoma. There is abundant immunologic and Karyotypic evidence indicating these neoplasms contain clonal expansions of a single functional subpopulation. ${ }^{[1]}$ Non Hodgkin Lymphoma are a Heterogenous group of Lymphoproliferative disorders which originates from the different cells of the Lymphoid system (B, T or Natural Killer Cells). ${ }^{[2]}$ Hodgkins Lymphoma is an entity which was first described by Thomas Hodgkin in 1832 and is characterized by the presence of classic Reed-Stern-berg cells and its variants in an appropriate cellular background It is broadly classified into classic and Nodular Lymphocyte predominant Hodgkin Lymphoma. $^{[3,4]}$ Malignant Lymphomas constitute $3.69 \%$ of all Malignancies World Wide. ${ }^{[5,6]}$

The aims and objectives of our study was as follows:-

i) To identify and provide an account of malignant lymphomas. ii) To classify the different types and subtypes using immunohistochemical markers.

\section{Materials and Methods}

This study included all the cases of Malignant Lymphoma diagnosed histologically during the period from November 2012 to July 2015 in the Department of Pathology of Assam Medical College and Hospital, Dibrugarh. This was a descriptive cross-sectional study done on 58 cases of Malignant Lymphomas diagnosed histologically during the period from November 2012 to July 2015 in the Pathology Department of AMCH Dibrugarh. The study included proper history, Clinical Examination, routine Haematological, Biochemical and Radiological investigations. A provisional diagnosis of Lymphoma was made and immunohistochemistry was performed from the paraffin embedded Tissue section using standard protocol. A panel of antibodies were decided based on morphologic differential diagnosis (no single marker is specific) which includes leukocyte common antigen (CD45), B-Cell markers (CD20 and CD79a), T-cell markers (CD3 and CD5) and other markers like CD23, bcl-2, CD10, cyclinD1, CD15, CD30, ALK-1, CD138 (based on cytoarchitectural pattern). 
The antibodies used in each case was according to the histological diagnosis made. An attempt was made in each case to classify it according to the proposed WHO Classification and working formulation.

\section{Result}

In this study we had diagnosed 58 cases of malignant lymphomas. Of these 47 cases (81\%) were Non Hodgkins Lymphoma and 11 cases (19\%) were Hodgkins Lymphoma. Out of these 58 cases of Malignant Lymphoma, adult cases were 51 and Paediatric cases were 7. The sex ratio male: female was 2.6:1 and NH:HL ratio was 4.3:1. Among 47 cases of Non Hodgkins Lymphoma 35 patients were Males (74.5\%) and 12 were female $(25.5 \%)$ with M:F ratio of 2.8:1. The age range was 2-76yrs.Among the Non Hodgkins Lymphoma B-Cell Lymphomas were the predominant type (35 cases) accounting for 74.5\% and T-Cell Lymphomas constituted 12 cases $(25.5 \%)$. In our study out of the Non Hodgkins Lymphoma Diffuse large B-Cell Lymphoma (DLBCL) was 15 cases $(42.86 \%$ ) followed by Follicular Centre Cell Lymphomas which accounted for 10 cases (28.57\%) and Mantle Cell Lymphoma comprises 5 cases (14.29\%). Extranodal marginal zone B-Cell Lymphomas
(MALT) which accounted for 3 cases (8.57\%) and Nodal marginal zone B-Cell Lymphoma which accounted for 2cases (5.71\%). Among the T-cell lymphomas, anaplastic large cell lymphoma (ALCL) was the most common subtype forming 5 cases (41.67\%), T-cell lymphoblastic lymphoma accounted for 3 cases (25\%), peripheral T-cell lymphomas (NOS) accounted for 3 cases (25\%) and Angioimmunoblastic lymphoma accounted for 1 case (8.33\%) of all T-cell Lymphoma cases respectively. In our study, Hodgkin lymphoma comprised of 11 cases, out of which Nodular sclerosis Hodgkin's lymphoma-4 cases forming $36.3 \%$ of all HL. Nodular lymphocyte predominance Hodgkin's lymphoma-3 cases (27.3\%), Mixed cellularity -2 cases (18.2\%), lymphocyte rich and lymphocyte depleted comprises One case each ( 9.1\%) .The lymphoma cases were also classified according to the site, Nodal and Extra-Nodal.Extra-Nodal cases were 16 which accounted for $35.6 \%$. The most frequently affected site was tonsil ( 5 cases, $31.25 \%$ ) followed by small and large intestine (4 cases, 25\%). Other sites were stomach ( 1 case, $6.25 \%$ ), appendix ( 1 case, $6.25 \%$ ), parotid ( 1 cases, $6.25 \%$ ), as nasal mass ( 1 cases, $6.25 \%$ ), brain (1case, $6.25 \%)$, bone ( 2 cases, $12.5 \%$ ).

Table 1: Distribution of Cases According to Different Parameters.

\begin{tabular}{|l|c|c|c|}
\hline \multicolumn{2}{|l|}{ Parameters } & Total Number & Percentage \\
\hline \multirow{2}{*}{ Age } & Adult Cases & $\mathbf{5 1}$ & $\mathbf{8 7 . 9 3 \%}$ \\
\cline { 2 - 4 } & Paediatric Cases (<18years) & $\mathbf{7}$ & $\mathbf{1 2 . 0 7 \%}$ \\
\hline \multirow{2}{*}{ Gender } & Male & $\mathbf{4 3}$ & $\mathbf{7 4 . 1 4 \%}$ \\
\cline { 2 - 4 } & Female & $\mathbf{1 5}$ & $\mathbf{2 5 . 8 6 \%}$ \\
\hline
\end{tabular}

Table 2: Malignant Lymphoma Diagnosis

\begin{tabular}{|l|c|c|}
\hline Type & Total Number & Percentage \\
\hline Non Hodgkins Lymphoma & 47 & $\mathbf{8 1 . 0 3 \%}$ \\
\hline Hodgkins Lymphoma & 11 & $18.97 \%$ \\
\hline
\end{tabular}

Table 3: Distribution of The Types of Nhl According to The Who Classification

\begin{tabular}{|l|c|c|}
\hline NHL Type & Total Number & Percentage \\
\hline \multicolumn{3}{|c|}{ B-Cell Lymphomas } \\
\hline Diffuse large cell B-cell & 15 & $42.86 \%$ \\
\hline Follicular lymphoma & 10 & $28.57 \%$ \\
\hline Mantle Cell lymphoma & 5 & $14.29 \%$ \\
\hline Extranodal marginal (MALT) lymphoma & 3 & $8.57 \%$ \\
\hline Nodal marginal Zone lymphoma & 2 & $5.71 \%$ \\
\hline \multicolumn{2}{|c|}{ T-Cell Lymphomas } \\
\hline ALCL & 5 & $41.67 \%$ \\
\hline Precursor & 3 & $25 \%$ \\
\hline Peripheral T-cell & 3 & $25 \%$ \\
\hline Angioimmunoblastic & 1 & $8.33 \%$ \\
\hline
\end{tabular}


Table 4: Hodgkins Lymphoma Diagnosis

\begin{tabular}{|c|c|c|}
\hline Type & Total Number & Percentage \\
\hline Nodular Sclerosis Hodgkins Lymphoma & 4 & $36.36 \%$ \\
\hline Nodular Lymphocyte predominance Hodgkins Lymphoma & 3 & $27.27 \%$ \\
\hline Mixed Cellularity & 2 & $18.18 \%$ \\
\hline Lymphocyte rich & 1 & $9.09 \%$ \\
\hline Lymphocyte depleted & 1 & $9.09 \%$ \\
\hline
\end{tabular}

Table 5: Extranodal NHL Distribution According to The Primary Site

\begin{tabular}{|l|c|c|}
\hline Extranodal site of NHL & Total Number & Percentage \\
\hline Tonsil & 5 & $31.25 \%$ \\
\hline Intestine (small and large) & 4 & $25 \%$ \\
\hline Bone & 2 & $12.50 \%$ \\
\hline Stomach & 1 & $6.25 \%$ \\
\hline Parotid & 1 & $6.25 \%$ \\
\hline Nose & 1 & $6.25 \%$ \\
\hline Brain & 1 & $6.25 \%$ \\
\hline Appendix & 1 & $6.25 \%$ \\
\hline
\end{tabular}

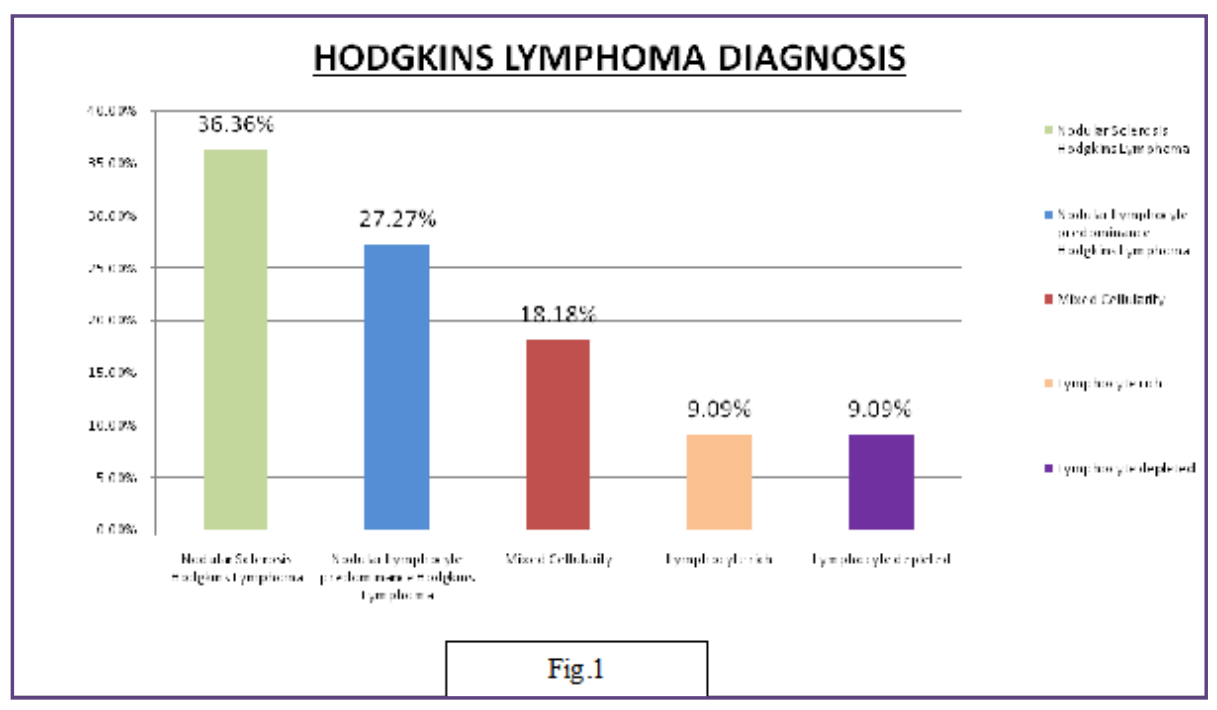

EXTRANODAL NHL DISTRIBUTION ACCORDING TO THE PRIMARY SITE

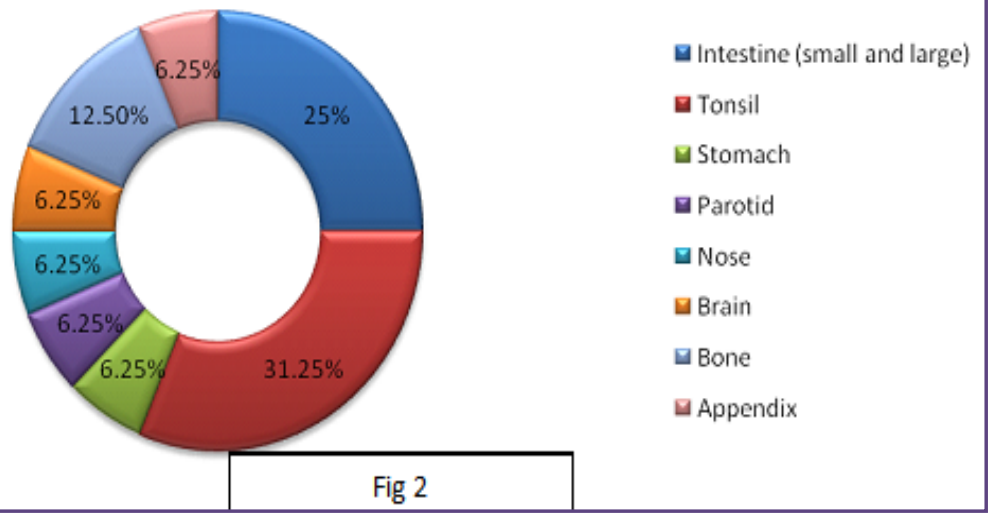

Annals of Pathology and Laboratory Medicine, Vol. 5, Issue 3, March, 2018 


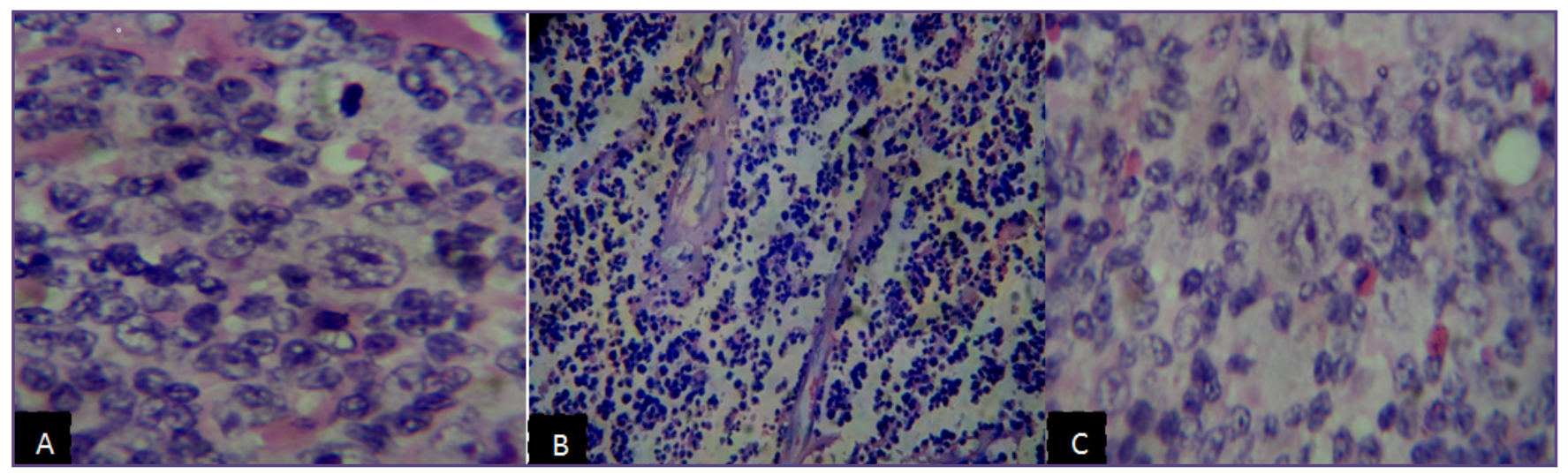

Fig. 1: Photomicroscopic picture showing (A) Diffuse Large B Cell Lymphoma (B) Mantle Cell Lymphoma (C) Hodgkins Lymphoma (Mixed Cellularity).

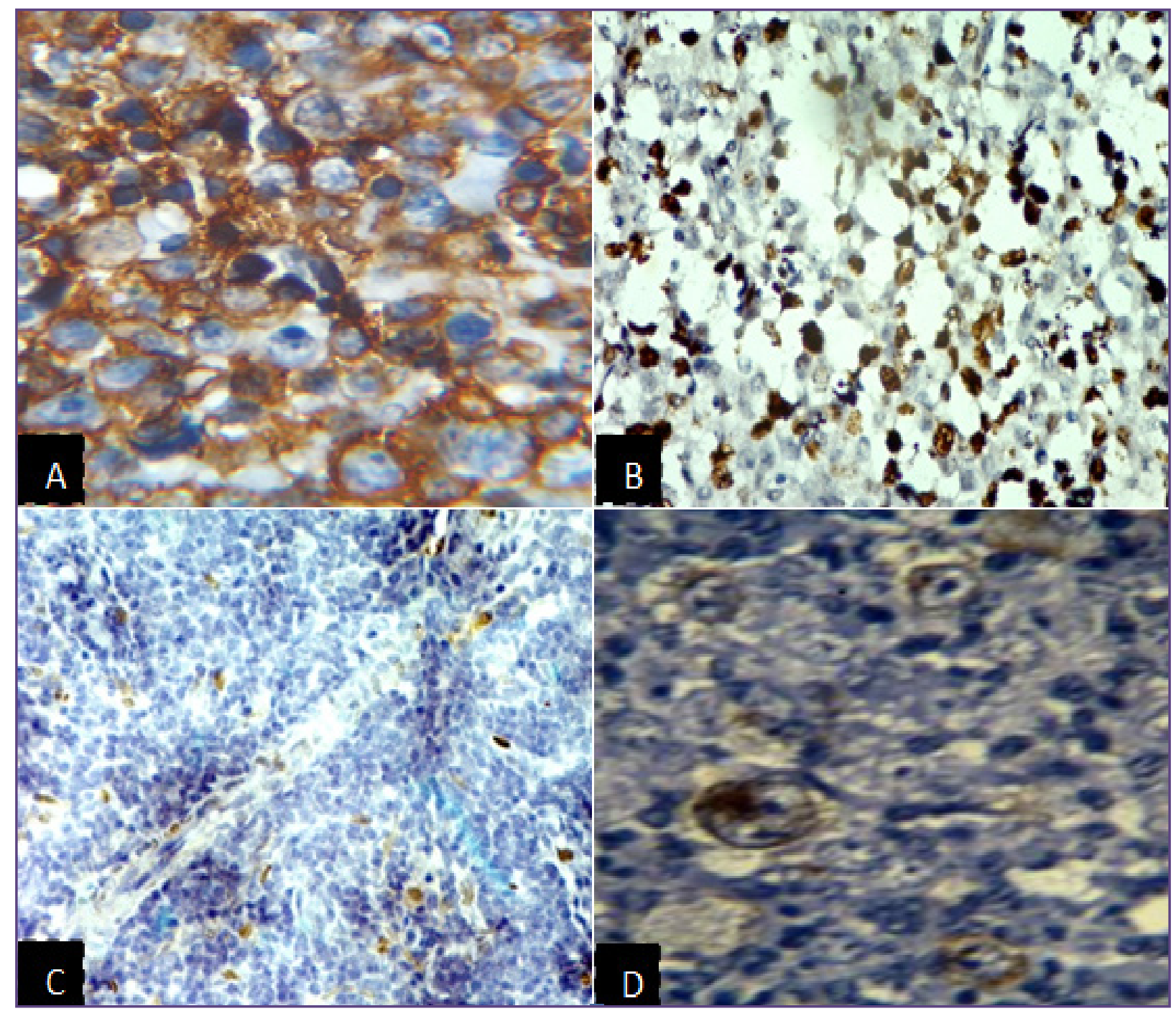

Fig. 2: Photomicroscopic picture showing (A) CD20 (+)ve in Diffuse Large B Cell Lymphoma (B) Ki67 (+)ve in Diffuse Large B Cell Lymphoma (C) Cyclin D1 (+)ve in Mantle Cell Lymphoma (D) CD30 (+)ve in Reed Sternberg Cell. 


\section{Discussion}

Malignant Lymphomas have been classified according to the latest classification of WHO 2016. ${ }^{[7]}$ Although there are limited alterations in the classification compared with 2008, the revised monograph will incorporate a large body of information published over the last 8 years relating to existing entities with some important diagnostic, prognostic, and therapeutic implications. The classification maintains the goals of helping to identify homogeneous groups of well-defined entities and facilitating the recognition of uncommon diseases that require further clarification. ${ }^{[7]}$ The revision clarifies the diagnosis and management of lesions at the very early stages of lymphomagenesis, refines the diagnostic criteria for some entities, details the expanding genetic/molecular landscape of numerous lymphoid neoplasms and their clinical correlates, and refers to investigations leading to more targeted therapeutic strategies. ${ }^{[6,7]}$ The WHO classification in combination with IHC evaluation the lymphomas are classified as Non hodgkins and Hodgkins lymphoma with further sub typing ${ }^{[8,9]}$ According to the cell type the Non Hodgkins Lymphoma can be B and T-Cell Type and this classification has prognostic significance to the Oncologist ${ }^{[10]}$. Our study showed $81 \%$ of Non Hodgkins Lymphoma and $19 \%$ of Hodgkins Lymphoma which was similar to the findings of (Manoj et al \& mandal et al) $76.3 \%$ and $23.7 \%$ respectively. ${ }^{[11,12]}$. The incidence of Hodgkins lymphoma was more lower in some Asian countries like Japan (7\%), Thailand $(8.5 \%)$ and china $(6.6 \%) \cdot{ }^{[13,14]}$ The proportion of Non Hodgkin Lymphoma was higher in the western world than in India which may be explained due to racial and genetic factors. ${ }^{[15]}$ Adults were more frequently involved than the Paediatric population and the male female ratio was 2.6:1 according to our study. In this study 47 cases were diagnosed as Non Hodgkins Lymphoma of which the male female ratio was 2.8:1which was consistent with the findings of Bhardwaj et al... ${ }^{[16]}$ In this study out of the 47 cases of Non-Hodgkins Lymphomas, B Cell lymphoma were the predominant type accounting to $74.5 \%$ and $\mathrm{T}$ Cell type were $25.5 \%$ which was consistent with the findings of Naresh et al in Mumbai (2000) which was $79.1 \%$ and $20.9 \%$ respectively. ${ }^{[17]}$ In our study out of the Non Hodgkins Lymphoma cases Diffuse large B-Cell Lymphoma (DLBCL) was 15cases (42.86\%) followed by Follicular Centre Cell Lymphomas which accounted for 10 cases (28.57\%) and Mantle Cell Lymphoma comprises 5 cases (14.29\%). Extranodal marginal zone B-Cell Lymphomas (MALT) which accounted for 3 cases $(8.57 \%)$ and Nodal marginal zone B-Cell Lymphoma which accounted for 2 cases $(5.71 \%)$. These findings were similar with the findings of mandel et al \& Roy et al ${ }^{[12,18]}$ Among the T-cell lymphomas, anaplastic large cell lymphoma (ALCL) was the most common subtype forming 5 cases $(41.67 \%)$ of all NHL. T-cell lymphoblastic lymphoma accounted for 3 cases (25\%), peripheral T-cell lymphomas (NOS) accounted for 3 cases (25\%) and Angioimmunoblastic lymphoma accounted for 1 case $(8.33 \%)$ of all NHL cases respectively. ${ }^{[9,19]}$ In our study, Hodgkin lymphoma comprising of 11 cases, out of which Nodular sclerosis Hodgkin's lymphoma-4 cases forming $36.3 \%$ of all HL. Nodular lymphocyte predominance Hodgkin's lymphoma-3 cases (27.3\%), Mixed cellularity -2 cases (18.2\%), lymphocyte rich and lymphocyte depleted comprises One cases ( $9.1 \%$ ) each which was similar to the findings of Bhardwaz et al \& Naresh et al. ${ }^{[16,17]}$

\section{Conclusion}

The present study tried to document the relative frequency of various types of Malignant lymphoma in this part of North East India. It has been seen that Non Hodgkins lymphoma was more prevalent than Hodgkins lymphoma. B-cell lymphomas were the predominant type with diffuse large B-cell lymphoma being more commoner among the different subtypes. While Anaplastic large cell lymphoma was more frequently encountered among the T-cell lymphomas. In studying the Hodgkins lymphoma Nodular Sclerosis was diagnosed more frequently. Extranodal lymphoma were also diagnosed with tonsil being the commonest site. A number of studies conducted in India and Worldwide suggests that the disease exhibits similar pattern with contrasting regional variations. An understanding of these patterns and differences may provide an insight into the Etiological factors and Pathogenesis of disease.

\section{Acknowledgements}

It is a great privilege for me to offer my sincer and heartfelt gratitude and respect to Prof. (Dr.) P. Saikia, MD, Professor \& Head, Department of Pathology, Assam Medical College $\&$ Hospital, Dibrugarh and also thankful to Ms. Sunia Roy for bringing out a beautiful and complete form of this manuscript.

\section{Reference}

1. Armitage Jo, Longo DL. Malignancies of Lymphoid cells. In: Braunwald E, Hayser S L, Fauci A S, Longo D L, Kasper D L, Jameson J L, Harrison's Principles of Internal Medicine:15th ed. New York: McGraw-Hills; 2001: 715-727.

2. Kumar V, Abbas AK, Aster JC. Diseases of White Blood Cells, Lymph Nodes, Spleen and Thymus. In V Kumar, A $\mathrm{K}$ Abbas, J C Aster. Robins and Cotran pathologic basis of disease, South Asia ed. New Delhi: Reed Elsevier India Private Limited; 2015 : 579-611. 
3. Mac Mohan B. Epidemiology of Hodgkins disease. Cancer Res. 1966; 26: 1189-1200.

4. Ioachim HL, Jeffrey L. Hodgkins Lymphoma In H L Ioachim, L Jeffrey. Ioachims's Lymph node pathology. Texas: Lippincott Williams \& Wilkins; 2008: 327-354.

5. Sriwatanawongasa V, Cardoso R, Chang P. Incidence of malignancy in peripheral lymph node biopsy. Am Surg 1985; 51 (10): 587-90.

6. Rosai J. Lymph nodes. In: Rosai Jeffrey, L Myers, John R. Goldblum, Laura W. Lamps. Rosai and Ackerman's Surgical Pathology. 10thed. St. Louis: Elsevier Mosby; 2011: 1877-2018.

7. Swerdlow SH, Campo E, Pileri SA, Harris NL, et al. The 2016 revision of the World health organization classification of lymphoid neoplasms. Blood. 2016; 127(20): 2375-2387.

8. Campo E, Swerdlow SH, Harris NL, Pileri S, Stein H, Jaffe ES. The 2008 WHO classification of lymphoid neoplasms and beyond: evolving concepts and practical applications. Blood. 2011; 117(19): 5019-5032.

9. Turner JJ, Hughes A M, Kricker A, Milliken S, Grulich A, Kaldor J, et al. Use of the WHO lymphoma classification in a population-based epidemiological study. Ann Oncol. 2004; 15: 631-7.

10. Chan JK, Roding S. Tumors of the lymphoreticular system: In Christopher D. M. Fletcher. Diagnostic histopathology of tumors, 4th ed. Churchill Living stone Elsevier, Philadelphia, $2013 ; 1343-1525$

11. Deka MK, Talukdar A, Tapkire R, Kanan R. Malignant Lymphoma in the Southern part of North East India ${ }^{\circledR}$ A Retrospective analysis of 101 cases. Journal of Science; 2015:5; 1256-1258.
12. Mandal SK, Mondal PK, Roy S D, Chattopadhyay S, Roy S, Biswas P K. Malignant lymphoma in Eastern India: A retrospective analysis of 455 cases according to World Health Organisation classification. Indian Journal of Medical and Paediatric Oncology. 2013:34;242-246.

13. Sukpanichnant S, Sonakul D, Piankijagum A, Wanachiwanawin W, Veerakul G, Mahasandana C, et al. Malignant lymphoma in Thailand. Changes in the frequency of malignant lymphoma determined from a histopathologic and immunophenotypic analysis of 425 cases at Siriraj Hospital. Cancer 1998:83;1197-1204.

14. Yin H F, Li T, Li J X. Retrospective analysis of 304 cases of malignant lymphomas in pathology. Study and practice of the WHO classification of lymphoid neoplasms. Zhonghua Yi Xue Za Zhi, 2003; 83:18 1556-60.

15. Balasubramaniam G, Saoba S, Sarade M, Pinjare S, et al. Case-control study of Risk Factors for Non-Hodgkin Lymphoma in Mumbai, India. Asian Pacific J Cancer Prev, 2013; 14 (2): 775-780.

16. Bhardwaj A, Kishore S, Kusum A. Comparative Analysis of the Distribution of Various Subtypes of Lymphoma Malignancies in Uttarakhand with other Regions in India. Indian Medical Gazette. 2012; April: 147-152.

17. Naresh KN, Srinivas V, Soman CS. Distribution of various subtypes of Non-Hodgkin's lymphoma in India: A study of 2773 lymphomas using R.E.A.L. and WHO Classifications. Annals of Oncology. 2000; 11: 63-67.

18. Roy A, Kar R, Basu D, Badhe B A. Spectrum of histopathologic diagnosis of lymph node biopsies: A descriptive study from a tertiary care centre in South India over 5 and $1 / 2$ years IJPM- 2013; 56 (2):103-108.

19. Baris D, Zahm S H. Epidemiology of lymphomas. Current Opinion in Oncology. 2000; 12(5): 383-394.

*Corresponding author:

Dr. Mondita Borgohain, 1st Floor Basic Science Building, Department of Pathology, Assam Medical College \& Hospital,

Dibrugarh, Assam: 786002 (India)

Phone: +91 9435139293

Email: monditaborgohain@gmail.com

Financial or other Competing Interests: None. 